\begin{tabular}{|c|c|c|}
\hline $\begin{array}{l}\text { ISSN 2525-4812 (versão online) } \\
\text { ISSN 2238-7641 (versão impressa) } \\
\text { http://www.revistaterceiramargem.com/ } \\
\text { index.php/terceiramargem/index }\end{array}$ & $\begin{array}{c}\text { Recebido em: 19/6/2019 } \\
\text { Aprovado em: 30/2/2020 } \\
\text { Período de publicação: jul/dez, } 2020\end{array}$ & $\begin{array}{c}\text { Revista Terceira } \\
\text { Margem Amazônia } \\
(\text { v. } 6 \cdot \mathrm{n} .15 \cdot \mathrm{Jul} / \mathrm{Dez} 2020)\end{array}$ \\
\hline
\end{tabular}

Como citar o artigo:

SILVA, C. A; SILVA, L. de S; BRITO, A. K. R; SOUZA, M. G; LIMA, A. M. de A. Conceito introdutório sobre sustentabilidade e desenvolvimento sustentável. Revista Terceira Margem Amazônia, v. 6, n.15, p. 195-205, 2020. Doi: http://dx.doi.org/10.36882/2525-4812.2020v6i15p195-205.

\title{
CONCEITO INTRODUTÓRIO SOBRE SUSTENTABILIDADE E DESENVOLVIMENTO* SUSTENTÁVEL
}

\author{
Carlos Augusto da Silval \\ Luciano de Souza Silva ${ }^{2}$ \\ Ane Karoline Rosas Brito ${ }^{3}$ \\ Maíra Gomes de Souza ${ }^{4}$ \\ Angela Maria de Araújo Lima
}

Resumo: O presente texto tem por base fazer uma breve descrição histórica sobre os eventos que ocorreram no sentido de elaborar propostas para serem difundidas entre os países membros das Nações Unidas, sobre uso racional dos recursos naturais, viáveis as populações presentes e que -, seja satisfatória às populações futuras a sustentabilidade. A dinâmica dos sabres das populações da Amazônia Central, quando ao tratamento dos recursos naturais é implacável. A história de interação do homem ao meio ambiente vem de longos milênios na região. Entretanto, o modelo de desenvolvimento foi terrível, pois, em pouco tempo, veio o esgotamento de algumas jazidas nos ambientes dos países industrializados europeus. Assim, novas áreas foram cogitadas, isto é, foi à parte Sul do Atlântico, o Novo Mundo, onde os recursos naturais e o homem foram gradativamente inseridos ao capital natural e econômico dos países do Norte a Europa. Nesse sentido, do uso em escala exponencial dos recursos, associado às transferências das populações

\footnotetext{
* Anais do Seminário Internacional em Ciências do Ambiente e Sustentabilidade na Amazônia, v. 5. Manaus: EDUA. 2018. ISSN 2178-3500

${ }^{1}$ Doutorado em Sociedade e Cultura na Amazônia (Ufam), voluntário do Programa de Pós-Graduação em Ciências do Ambiente e dos Laboratórios de Arqueologia e Socioambiental-Ufam, Bolsista do TCE-AM: casilva@ufam.edu.br

${ }^{2}$ Bacharel em Arqueologia pela UNIVASF e Mestre em Arqueologia pelo Programa de Pós-Graduação em Arqueologia da UFPE. Vínculo institucional: Arqueólogo do Setor de Arqueologia do Museu Câmara Cascudo, da UFRN. Colaborador do Museu Amazônico: lucianoarque @ yahoo.com.br

${ }^{3}$ Bacharel em Turismo pela FAMETRO - Faculdade Metropolitana de Manaus. Colaboradora do Núcleo de Socioeconomia da Faculdade de Ciências Agrárias da Ufam.

${ }^{4}$ Graduada em Pedagogia pela Universidade - UNINORTE. Professora Formadora da Escola da Terra da Faculdade de Educação-FACED-UFAM.

${ }^{5}$ Graduada em Arqueóloga pela Universidade do Estado do Amazonas -UEA (2013), angelamariaaraujodelima@hotmail.com
} 
humanas de áreas rurais, para zonas urbanas, ou seja, processo de migrações promoveu profundas mudanças nos três grandes ecossistemas do planeta terra, são eles: terrestre, aquático e atmosférico. $\mathrm{O}$ exagero de uso causou à escassez dos recursos, além dos eventos climáticos, (tsunamis, furações, enchente, secas, etc.) que desestabilizaram centenas e milhares de pessoas no mundo. Nesse sentido, as Nações Unidas, a partir do final dos anos de 1960, a alçaram a necessidade, que os países desenvolvidos contribuíssem para estabilidade dos ecossistemas. Assim, a ONU - Organização das Nações Unidades semeia acordos sistêmicos, ou seja, às convenções normativas entre os países membros, no sentido de implantar o imaginário desenvolvimento sustentável.

Palavras-chave: adaptabilidade; agricultura familiar; na Amazônia Central.

Abstract: The present text is based on a brief historical description of the events that took place in the sense of elaborating proposals to be disseminated among the member countries of the United Nations, on the rational use of natural resources, viable the populations present and that - populations. The dynamics of the sabers of the populations of the Central Amazon, when the treatment of natural resources is relentless. The history of man's interaction with the environment comes from long millennia in the region. However, the development model was appalling, since, in a short time, there was the depletion of some deposits in the environments of the European industrialized countries. Thus, new areas were considered, that is, to the South Atlantic, the New World, where natural resources and man were gradually inserted into the natural and economic capital of the countries of the North to Europe. In this sense, the use of resources on an exponential scale, associated with the transfer of human populations from rural areas to urban areas, that is, the migration process has led to profound changes in the three major ecosystems of the planet Earth: terrestrial, aquatic and atmospheric. Exaggeration has led to scarce resources, as well as climatic events (tsunamis, hurricanes, floods, droughts, etc.) that have destabilized hundreds and thousands of people around the world. In this sense, the United Nations, since the late 1960s, has raised the need for developed countries to contribute to the stability of ecosystems. Thus, the United Nations - Nations Organization sows systemic agreements, that is, to the normative conventions among the member countries, in order to implant the imaginary sustainable development.

Keywords: Concepts; adaptability; family farming in Central Amazonia.

\section{INTRODUÇÃO}

Este tema é de extrema complexidade, pois, traça caminhos que ao longo das décadas veem sendo deliberado pelos países membros das Nações Unidas, de cujas diretrizes ou preocupações são uso racional dos recursos naturais existentes no planeta terra. Todavia, só a partir da primeira década dos anos de 1970, onde a (ONU) formalizaram eventos, no sentido de reparar o consumo exagerados do meio ambiente (recursos naturais), Enríques (2010, p. 15). O presente texto tem por base fazer uma 
SILVA, C. A. da; SILVA, L. de S; BRITO, A. K. R; LIMA, A. M. de A.

breve descrição histórica sobre os eventos que ocorreram no sentido de elaborar propostas para serem difundidas entre os países membros das Nações Unidas, sobre uso racional dos recursos naturais, viáveis as populações presentes e que -, sejam satisfatórias às populações futuras a (sustentabilidade). E, a dinâmica dos sabres das populações da à Amazônia Central, quando ao tratamento dos recursos naturais.

\section{A INTERAÇÃO ENTRE O HOMEM E O AMBIENTE}

A história de interação do homem ao meio ambiente vem de longos milênios. O manejo principalmente, na margem Norte do Atlântico, no (Velho Mundo), foi predominante predatório no que tange aos recursos naturais, Sirvinskas (2009, p.32). O uso em escala exponencial ocorreu com o alargamento do advento da Revolução Industrial, nas quais os recursos ou jazidas foram sacrificados em favor do desenvolvimento econômico Stahel (1995, p. 105). O modelo de desenvolvimento foi terrível, pois, em pouco tempo, veio o esgotamento de algumas jazidas nos ambientes dos países industrializados (europeus). Assim, novas áreas foram cogitadas, isto é, foi à parte Sul do Atlântico, o (Novo Mundo), onde os recursos naturais e o homem foram gradativamente inseridos ao capital natural e econômico dos países do Norte (Europa). A somatória dos recursos enriqueceu os estoques de recursos às nações colonialistas europeias. Todavia, às nações utilizaram os recursos sem, [...] "nenhuma consciência da necessidade de respeitar a natureza", (SOARES, 2003, p. 15).

Nesse sentido, do uso em escala exponencial dos recursos, associado às transferências das populações humanas de áreas rurais, para zonas urbanas, ou seja, processo de (migrações), promoveu profundas mudanças nos três grandes ecossistemas do planeta terra, são eles: "terrestre, aquático e atmosférico" (SIRVINSKAS, p.5). As mudanças, gradativamente, contribuíram para sérios desequilíbrios no ambiente, - e as consequências são, hoje, visíveis nas cidades, vilas, comunidades que estão próximos dos mares, rios etc., nos continentes.

O exagero de uso causou à escassez dos recursos, além dos eventos climáticos, (tsunamis, furações, enchente, secas, etc.) que desestabilizaram centenas e milhares de pessoas no mundo. Nesse sentido, as Nações Unidas, a partir do final dos anos de 1960, a alçaram a necessidade, que os países desenvolvidos contribuíssem para estabilidade dos ecossistemas. Assim, a (ONU - Organização das Nações Unidades), semeia acordos 
sistêmicos, ou seja, às (convenções normativas) entre os países membros, no sentido de implantar o imaginário desenvolvimento sustentável.

$\mathrm{Na}$ sequência os apontamentos das convenções que deram o início ao "conceito de desenvolvimento sustentável" (BRUSEKE, p. 34), no qual a semântica, pleiteia o uso dos ecossistemas sustentáveis, isto é, consumir os recursos naturais, mas, com precaução e segurança dos bens culturais, para que, as futuras gerações tenham os mesmos direitos de presenciar e usufruir dos "patrimônios naturais e culturais" (SOARES, 2003, p.153) e dos "patrimônios genéticos" (SIRVINSKAS, p. 503).

Os patrimônios naturais e culturais são na verdade -, os monumentos físicos, que são: as obras da natureza e do homem, tais como: (da natureza, as cavernas, as cachoeiras, as paisagens, as florestas, os rios, os peixes, etc.,) e do (homem, os sítios arqueológicos, as edificações antigas, modernas e contemporâneas, etc.). Porém, antes de adentrar propriamente ditas nas convenções ambientais, vale destacar a atuação do gênero beiradino (homem/mulher) da Amazônia Central, com uma espécie de prática pedagogia do tempo. O tempo de cheia e de seca dos rios, onde o marcador do tempo, o (relógio) são os concertos (cantos) das aves que migram nas duas estações (cheia e seca) nos ecossistemas de várzeas e terras firmes nas quais são realizadas atividades produtivas (agricultura familiar, pescarias, extração de açaí, bacaba, etc.).

Os patrimônios existentes na Amazônia Central (Genético e Cultural), a pesar da degradação ambiental ao longo dos últimos cinco séculos de ocupação dos colonizadores, vêm resistindo pressões de magnitudes brutais, porém, a intervenção das populações humanas contemporâneas que interagem as margens dos rios, lagos, furos, nas florestas distantes dos grandes rios da região.

\section{Caminhos deliberativos sobre o conceito de desenvolvimento sustentável}

A trilha em busca do conceito de Desenvolvimento Sustentável, na verdade, a pilastra começa por meio de discussão a partir do "Clube de Roma" (BRUSEKE, 1995, p. 29). Em 1972, a reunião de Estocolmo de especialistas nas questões ambientais e de economistas renomados expõem os problemas sobre os modelos econômicos advindo do modelo pós-revolução industrial, que se apresentava como uma moenda frente aos recursos naturais.

Nesse sentido, a comissão mundial regida pela (ONU), publicou o Relatório Brundtland, criando a expressão "Desenvolvimento Sustentável” (BRUSEKE, 1995, p. 33). O relatório discorria sob as diretrizes que os países desenvolvidos e em 
desenvolvimentos teriam de seguir metas socioeconômicas e ecológicas benéfico às gerações presente, além de promover às seguridades para as populações futuras, assim, o enunciado do relatório ficou referendado de: o nosso futuro comum, de cujas linhas mestras sinalizam as diretrizes que os países parceiros deveriam se comprometer com as seguridades, social, econômica e ecológica. Na tabela 1 listaram-se sumariamente as diretrizes do relatório.

Tabela 1: Metas referenda no Relatório Brundtland (1987).

\begin{tabular}{|c|c|c|}
\hline Ordem & Ações & Características \\
\hline 01 & Desacelerar índices de natalidade. & $\begin{array}{l}\text { Diminuir a pressão aos recursos naturais, não } \\
\text { renováveis. }\end{array}$ \\
\hline 02 & $\begin{array}{l}\text { A seguridade à alimentação por } \\
\text { tempo indeterminado. }\end{array}$ & $\begin{array}{l}\text { A distribuição de renda igualitária entre as } \\
\text { populações do norte e do sul }\left(1^{\circ} 2^{\circ} \text { e } 3^{\circ} \text { mundo). }\right.\end{array}$ \\
\hline 03 & $\begin{array}{l}\text { A manutenção da biodiversidade dos } \\
\text { ecossistemas da terra. }\end{array}$ & $\begin{array}{l}\text { Os países parceiros elaborar planos para a } \\
\text { preservação de áreas biológicas, (REBIO, } \\
\text { UNIDADES DE CONSERVAÇÃO, etc.). }\end{array}$ \\
\hline 04 & A diminuição de demanda de energia. & Projetos para produzir energia renovavam. \\
\hline 05 & $\begin{array}{l}\text { Crescimento industrial nos países em } \\
\text { desenvolvimento. }\end{array}$ & Projetos de cunhos ecológicos. \\
\hline 06 & Encurtar a proliferação urbana. & Visibilidade entre áreas urbanas e rurais (contato). \\
\hline 07 & $\begin{array}{l}\text { Presença de políticas pública básicas. } \\
\text { E, metas as instituições em níveis } \\
\text { nacionais e internacionais. }\end{array}$ & Acesso à escola, transportes, saúde, lazer, etc. \\
\hline 08 & $\begin{array}{l}\text { As diretrizes tem que ser direcionados } \\
\text { ao desenvolvimento Sustentável pelas } \\
\text { instituições parceiras do programa. }\end{array}$ & $\begin{array}{l}\text { As organizações devem promover procedimentos } \\
\text { salutares à sustentabilidade. }\end{array}$ \\
\hline 09 & $\begin{array}{l}\text { Os países membros do programa } \\
\text { devem proteger os ecossistemas } \\
\text { Antártico, oceanos etc. }\end{array}$ & $\begin{array}{l}\text { Os ecossistemas polares e oceanos são objetos de } \\
\text { preservações em níveis nacionais e internacionais. }\end{array}$ \\
\hline 10 & $\begin{array}{l}\text { As guerras devem ser definitivamente } \\
\text { abolidas. }\end{array}$ & $\begin{array}{l}\text { Espaços democráticos deve ser atributo entre os } \\
\text { países membros. }\end{array}$ \\
\hline 11 & $\begin{array}{l}\text { As Nações Unidas devem viabilizar o } \\
\text { desenvolvimento sustentável. }\end{array}$ & $\begin{array}{l}\text { O programa de sustentabilidade horizontal entre os } \\
\text { pais do norte e sul. }\end{array}$ \\
\hline
\end{tabular}

Fonte: Bruseke (1995, p. 33). Elaboração: Carlos Augusto da Silva, mar., 2014.

Os itens assinalados na tabela 1 -, foi um esboço traçado pela comissão a (ONU) que minutava as metas do programa que os países desenvolvidos em desenvolvimento deveriam proceder, no sentido de conhecer e preservar os ecossistemas que ainda apresentavam grandes demandas de recursos. Além, também de indicar procedimentos quanto ao mote que as nações procederiam quanto ao desenvolvimento sustentável de potencial energético, no qual pleiteava técnicas eminentemente ecológicas. No entanto, as metas teriam validade ou repulsadas, pois, após 20 (vinte) anos, outra reunião foi lançada para traçar novas metas e se as metas de 1972 foram salutares ao meio ambiente 
SILVA, C. A. da; SILVA, L. de S; BRITO, A. K. R; LIMA, A. M. de A.

e as questões de sustentabilidade as populações humanas foram almejadas. Assim, em 1992, no Brasil, ocorreu a Cúpula da Terra, ou a Rio-92 ou ECO-92.

\section{A Cúpula da Terra - Rio-92 ou ECO-92}

Em 1992, o Brasil recém-libertado das garras do governo militar que perdurou de 1967 a 1985. E, em 02 de outubro de 1992, o presidente Fernando Collor de Melo, primeiro presidente eleito pós-ditadura militar. Todavia, por acusações de corrupção foi lhe aplicado o impedimento (impeachment), assumindo a chefia de governo, o VicePresidente Itamar Franco.

Mas, os preparativos para recepcionar o vento vinham sendo viabilizado por bom tempo, pois, o presidente Fernando Collor de Melo, fez uma espécie de mudança da capital do Brasil, isto é, em junho de 1992, a cidade do Rio de Janeiro foi o centro das atenções, não só pelas questões administrativas como também para a segurança dos chefes de governos que se fizeram presente no evento.

A ECO-92 foi um marco conceitual para o desenvolvimento sustentável, o evento organizado pelo (ONU- Organização das Nações Unidas) e pelas instituições do Estado Brasileiro, conseguiram postular novos procedimentos, quanto as questões sociais, ambientais e ratificar algumas das clausulas inferidos na reunião de Estocolmo em 1972. No evento estiveram presentes "delegados de 172 países e 108 chefes de Estados" (BRASIL, 2012, p. 2), além de centenas de representantes de entidades não governamentais (ONGS) e jornalistas de toda parte do mundo.

As ações retiradas durante as reuniões foram: 1) A convenção sobre as questões climáticas; 2) A convenção sobre as diversidades biológicas; 3) As questões de preservações das florestas; 4) A convenção sobre o meio ambiente e o desenvolvimento; 5) A criação da à Agenda 21. (Ministério do Meio Ambiente, 2012, p. 4), as convenções deliberam 27(vinte e sete) princípios ou guia que os países deverão seguir. Na tabela 2 listaram-se as características cabíveis sobre as ações que os Estados e a sociedade civil possam seguir a partir da à Agenda 21.

Tabela 2: As súmulas dos 27 princípios da Eco-92 para o mundo.

\begin{tabular}{|c|l|l|}
\hline Ordem & \multicolumn{1}{|c|}{ Princípios } & \multicolumn{1}{c|}{ Características } \\
\hline 01 & $\begin{array}{l}\text { O homem deverá ter atenção } \\
\text { primordial quanto à necessidade de } \\
\text { vida profícua. }\end{array}$ & $\begin{array}{l}\text { O uso racional dos recursos naturais de tal forma } \\
\text { que esteja em consonância à natureza. }\end{array}$ \\
\hline 02 & $\begin{array}{l}\text { O uso dos recursos naturais em } \\
\text { conformidades as políticas dos des } \\
\text { Estados Nacionais. }\end{array}$ & $\begin{array}{l}\text { A utilização dos recursos deve ter padrões, que não } \\
\text { interfira em outros Estados, ou em limites } \\
\text { internacionais. }\end{array}$ \\
\hline
\end{tabular}




\begin{tabular}{|c|c|c|}
\hline 03 & $\begin{array}{l}\text { O desenvolvimento deverá ser prático } \\
\text { e sociável. }\end{array}$ & $\begin{array}{l}\text { A utilização dos recursos será controlável, sem, } \\
\text { contudo prejudicar as futuras gerações. }\end{array}$ \\
\hline 04 & $\begin{array}{l}\text { O desenvolvimento sustentável terá } \\
\text { caráter social e democrático. }\end{array}$ & $\begin{array}{l}\text { A proteção ambiental tem que ser socializada pelas } \\
\text { instituições públicas e privada. }\end{array}$ \\
\hline 05 & $\begin{array}{l}\text { Ações associativas para melhorar as } \\
\text { condições de vidas em níveis } \\
\text { nacionais e internacionais. }\end{array}$ & $\begin{array}{l}\text { As instituições públicas e a sociedade civil em } \\
\text { níveis nacionais e internacionais devem sem } \\
\text { empenhar na promoção de padrões de vidas dignas. }\end{array}$ \\
\hline 06 & $\begin{array}{lll}\begin{array}{l}\text { Prioridades aos países em } \\
\text { desenvolvimento. }\end{array} & & \\
\end{array}$ & $\begin{array}{l}\text { O desenvolvimento tem que atingir todos os } \\
\text { Estados em nível mundial. }\end{array}$ \\
\hline 07 & $\begin{array}{l}\text { A cooperação dos Estados } \\
\text { Desenvolvidos, para melhorar as } \\
\text { condições dos ecossistemas em nível } \\
\text { internacional. }\end{array}$ & $\begin{array}{l}\text { Deliberar que os países desenvolvidos se } \\
\text { comprometam para o melhoramento do meio } \\
\text { ambiente. }\end{array}$ \\
\hline 08 & O uso insustentável dos recursos. & A promoção de políticas demográficas. \\
\hline 09 & $\begin{array}{l}\text { A cooperação técnica entre os } \\
\text { Estados. }\end{array}$ & $\begin{array}{l}\text { As tecnologias ecológicas deverão ser socializadas } \\
\text { no sentido de preservar o meio ambiente. }\end{array}$ \\
\hline 10 & $\begin{array}{l}\text { As informações democráticas quanto } \\
\text { à preservação do meio ambiente. }\end{array}$ & $\begin{array}{l}\text { As sociedades públicas e civis deram seguir trilhas } \\
\text { para estimular a conscientização do uso do meio } \\
\text { ambiente. }\end{array}$ \\
\hline 11 & $\begin{array}{l}\text { Os Estados promoverão políticas } \\
\text { ambientais distintas e sociáveis. }\end{array}$ & $\begin{array}{l}\text { As normas deverão a atender as questões } \\
\text { ambientais. }\end{array}$ \\
\hline 12 & $\begin{array}{l}\text { A cooperação econômica em níveis } \\
\text { internacionais. }\end{array}$ & O crescimento econômico deverá ser linear. \\
\hline 13 & $\begin{array}{l}\text { A penalidade promovida pelos } \\
\text { Estados contra a poluição e outra } \\
\text { agressão ao ambiente. }\end{array}$ & $\begin{array}{l}\text { O direito internacional quando houver a } \\
\text { degradação ambiental fora do território de } \\
\text { determinado pais. }\end{array}$ \\
\hline 14 & $\begin{array}{l}\text { A cooperação quando houver a } \\
\text { poluição por substancia no ambiente. }\end{array}$ & $\begin{array}{l}\text { A cooperação dos Estados quanto à prevenção à } \\
\text { saúde humana. }\end{array}$ \\
\hline 15 & $\begin{array}{l}\text { As prevenções ao ambiente deverão } \\
\text { ser amplamente de interesse dos } \\
\text { Estados. }\end{array}$ & $\begin{array}{l}\text { Em caso de dúvida sobre qualquer atividade ao } \\
\text { meio ambiente. Este não será realizado. }\end{array}$ \\
\hline 16 & $\begin{array}{l}\text { As instituições públicas deverão } \\
\text { informar aos internacionalizar os } \\
\text { custos ambientais. }\end{array}$ & $\begin{array}{l}\text { As entidades poluidoras têm de arcar com os } \\
\text { custos. }\end{array}$ \\
\hline 17 & $\begin{array}{l}\text { Impacto ao ambiente é tarefa dos } \\
\text { Estados. }\end{array}$ & $\begin{array}{l}\text { Deverá haver autoridades no assunto quanto ao } \\
\text { estudo de impacto. }\end{array}$ \\
\hline 18 & $\begin{array}{l}\text { A cooperação em casos de desastres } \\
\text { naturais. }\end{array}$ & $\begin{array}{l}\text { Os Estados se juntaram para amenizar quaisquer } \\
\text { impactos naturais em outros Estados. }\end{array}$ \\
\hline 19 & $\begin{array}{l}\text { As atividades impactantes em zona de } \\
\text { fronteiras. Os Estados notificaram as } \\
\text { atividades potencialmente } \\
\text { impactantes. }\end{array}$ & As diplomacias serão as âncoras da "boa fé". \\
\hline 20 & $\begin{array}{l}\text { O gênero feminino terá papel } \\
\text { fundamental na preservação do } \\
\text { ambiente. }\end{array}$ & A importância para sustentabilidade. \\
\hline 21 & $\begin{array}{l}\text { Os jovens serão peça fundamental } \\
\text { para o desenvolvimento por meio de } \\
\text { criatividades. }\end{array}$ & O futuro depende de esforços de todos. \\
\hline 22 & \begin{tabular}{lll} 
As comunidades & \multicolumn{2}{c}{ indígenas, } \\
tradicionais e & outras & tem papel \\
fundamental & na & conservação \\
ambiental. & & \\
\end{tabular} & $\begin{array}{l}\text { Os Estados deverão assegurar por meio de políticas } \\
\text { públicas para o alcance do desenvolvimento } \\
\text { sustentável. }\end{array}$ \\
\hline 23 & $\begin{array}{l}\text { A proteção ao meio ambiente é tarefa } \\
\text { das esferas sociais. }\end{array}$ & $\begin{array}{l}\text { A proteção a todo custo aos ambientes aos povos } \\
\text { nele submetido. (Unidades de Conservação, etc.). }\end{array}$ \\
\hline 24 & $\begin{array}{l}\text { A guerra é evento prejudicial ao } \\
\text { ambiente. Os Estados deverão por } \\
\text { conseguida respeitar o direito } \\
\text { internacional. }\end{array}$ & $\begin{array}{l}\text { Em tempo de guerra os Estados em comum acordo } \\
\text { se juntarão para a promoção do desenvolvimento } \\
\text { sustentável. }\end{array}$ \\
\hline
\end{tabular}


SILVA, C. A. da; SILVA, L. de S; BRITO, A. K. R; LIMA, A. M. de A.

\begin{tabular}{|c|l|l|}
\hline 25 & $\begin{array}{l}\text { A proteção ao ambiente é } \\
\text { indissociável. }\end{array}$ & $\begin{array}{l}\text { A visibilidade ao ambiente é promover à segurança } \\
\text { a paz etc. }\end{array}$ \\
\hline 26 & $\begin{array}{l}\text { Os Estados serão os árbitros quanto à } \\
\text { proteção ambiental. }\end{array}$ & $\begin{array}{l}\text { A Organização das Nações Unidades (ONU) é } \\
\text { promoverá a conservação do meio ambiente. }\end{array}$ \\
\hline 27 & $\begin{array}{l}\text { Os Estados e entidades públicas e } \\
\text { civis serão responsáveis por esta } \\
\text { "Declaração". }\end{array}$ & $\begin{array}{l}\text { O campo do desenvolvimento Internacional e } \\
\text { sustentáveis são providos de âncoras democráticas. }\end{array}$ \\
\hline
\end{tabular}

Fonte: Ministério do Meio Ambiente, Brasil. Disponível em:〈www.mma.gov.br.>. Acesso em: mar., 2014. Organizado por: Carlos Augusto da Silva.

Os vinte e sete princípios da Rio-92, deliberados pela (ONU - organização das Nações Unidas), no que tange a prevenção do meio ambiente, alguns deles já estavam inseridos pela Política Nacional do Meio Ambiente no Brasil, Sirvinskas (2009, p.133). O sistema foi fundamentado pela lei de $n^{\circ} 6.938$, de 31 de agosto de 1981 . A lei instituição o (SISNAMA) que instituiu órgãos básicos para institucionalizar as diretrizes e princípios instituídos pela Constituição Federal de 1988, em seu art. 225.

A Política Nacional do Meio Ambiente, também instituiu 10 (dez) princípios básicos fundamentados nos princípios de conservação e manutenção dos ecossistemas brasileiros. O décimo princípio, trata exclusivamente sobre a Educação Ambiental, cujos objetivos de instruir o cidadão em todos os níveis de ensino, no diz respeito ao art. $225 \S$ $1^{\circ}$, na "defesa do meio ambiente" (SIRVINSKAS, 2009, p. 136). A seguir breve descrição do processo de sustentabilidades ou de sabres que são gestados pelas populações humanas que habitam as margens dos rios na Amazônia Central.

\section{Saberes ou Sustentabilidade humana na Amazônia Central}

Desde a primeira expedição colonizadora que desceu o Rio Amazonas, no qual fez relevantes apontamentos de processo de ocupações dos espaços pelas populações indígenas que habitavam as margens dos rios desde faz do rio Napo e áreas adjacentes do rio Solimões-Amazonas, Carvajal (1941, p. 12). As áreas ocupadas tratam-se dos ecossistemas de várzeas e de terras firmes, Fonseca (2011, p. 54). Nessas áreas, além de haver sequências de habitações adaptáveis ao ambiente, Moran (1990, p. 26), também havia variedades de cultivos agrícolas que foram ofertados ou surrupiados pelos expedicionários.

Os cultivos agrícolas realizados pelas famílias indígenas, caboclo-ribeirinhas ou tradicionais, Fraxe (2010, p.56) residentes nas margens dos rios da região tradicionalmente, chamados pelas populações de "plantios ou cultivos de várzeas" vem de logo período, de cujo modelo possivelmente, vem das sociedades pré-colombianas. Às 
várzeas tem grande potencial de produção agrícola. As plantações ocorrem em conformidades com a descida d'águas, geralmente, a partir do final do mês de julho e até dias de setembro. E, nos meses de novembro a fevereiro, inicia o processo de colheitas.

As plantadas cultivadas nas "praias", "estirões" ou nas curvas dos rios. Esses espaços de aluviões, Fonseca (2011, p.140). São na verdade, grandes filetes de solo, que divide a várzea da terra firme ao longo dos rios. Neles, são plantadas variedades de espécies tais como: maxixe, jerimuns, feijão de praias conhecidos de "quarenta dias de coloração arroxeado e branco", melão, melancia, milho, manivas de onde são retiradas a macaxeira e a mandioca amarga, tomates, pimenta, doce, cebolinhas, cheiro-verde, couve, chicórias, etc.

Essas culturas são adicionadas nas dietas limitares das famílias consorciadas às variedades de espécies de peixes, dentre elas: pacu, matrinchã, aruanã, diversas espécies de caras, pirapitinga, diversas especeis de aracus, acari bodó, branquinha, traíra, pirarara, surubim, caparari, etc. As espécies são pescadas na entressafra de piracemas, porém no período defeso os exemplares são conservados em lagos, paranás, rios da região. E, o que não são destinados à dieta alimentar da de peixes ou os produtos da agricultura familiar Noda (2007, p.56), são destinados às vilas e cidades próximos das comunidades.

A sobra ou excedente de produtos, isto é, os produtos agrícolas, farinhas de mandioca, piracuí (farinha de peixe), melancias, jerimuns, etc., são transportadas em barcos conhecidos como o "motor de linha" ou em pequenas canoas, movida a motor rabeta. As figuras 3 e 4 configuram ou corroboram ao sistema de adaptabilidades e sustentabilidades das populações da Amazônia Central no (Estado do Amazonas), que a cada ano nutrem as vidas humanas e da biodiversidade na região.

Figura 3: Barco Regional ou o motor de linha, recebendo carga de produtos da várzea, (banana, melancia, jerimum).

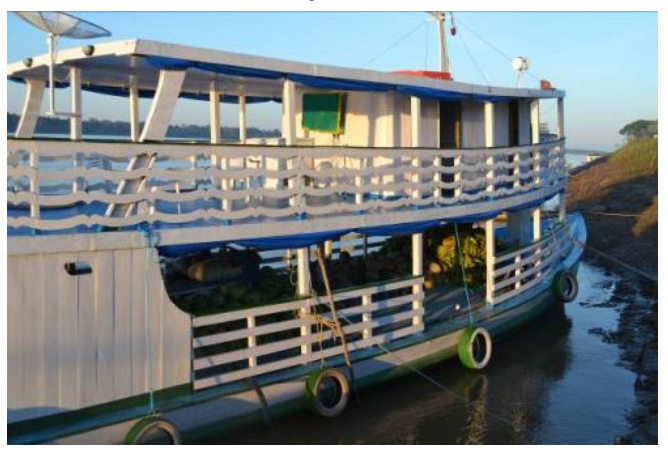

Foto: Carlos Augusto da Silva, fev., 2012.

Figura 4: Edificação indígena (maloca) residência típica de adaptação e sustentabilidade na região. 
SILVA, C. A. da; SILVA, L. de S; BRITO, A. K. R; LIMA, A. M. de A.

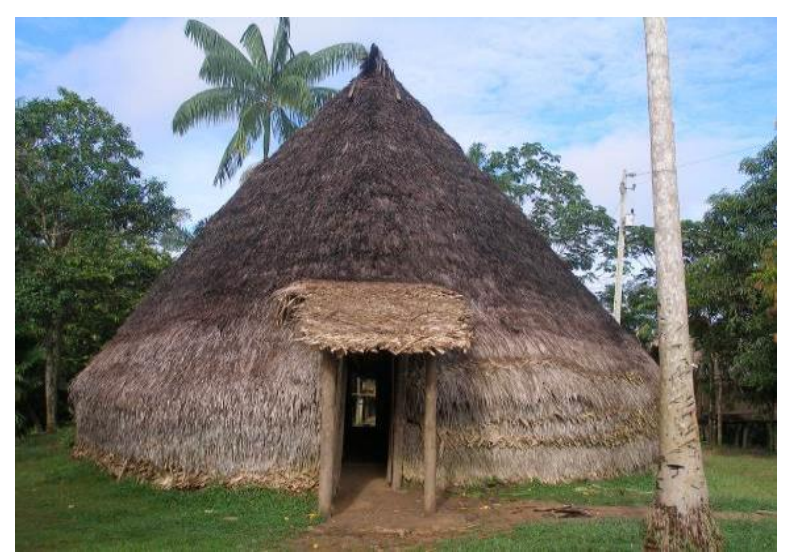

Foto: Carlos Augusto da Silva, fev., 2012.

As figuras são uma espécie de janela de como as populações ao longo de anos vem interagindo com a subida e descidas d’águas na região. À água, a terra e a floresta funcionam como uma poupança, pois, a cada mergulho a cada seis meses que fica submersa se regenera. E, as famílias de agricultores, as horas de trabalho são também por cerca de seis meses. A outra parte do ano as famílias realizam outras atividades, um exemplo, são os roçados do centro que ficam nas áreas de terra firme.

Assim, para quem visita uma residência de produtor familiar, a avaliar que o sistema de produção agrícola só realizado em áreas de várzeas, mas, na verdade são realizados em dois planos. Assim, as famílias que planejam as produções agrícolas têm o ano todas as espécies. Pois, quase que a maioria das roças do centro é cultivada em área de solo de terra preta. O solo de terra preta tem alto potencial agrícola, assim, no solo são produzidos milho, mamão, maxixe, quiabos, etc.

Portanto, pode-se a avaliar que as famílias de agricultura conseguiram ao longo de anos atividades sustentáveis, pois, tanto nas áreas de várzeas e de terras firmes, nas quais elaboram engenhoso sistema de produção, que garante uma dieta alimenta salutar em círculo, ou seja, o ano inteiro, com a abundância.

\section{CONSIDERAÇÕES FINAIS}

Trabalhar conceito é complexo, pois, nem sempre os conceitos atingem as metas previamente introduzidas no sentido de aspirar ou certificar determinado tema. No que tange ao cansado e debatido "desenvolvimento sustentável", (SIRVINSKAS, 2009, p. 383), nas quais as convenções deliberadas pela (ONU-Organização das nações Unidas) que colocara à luz os problemas ambientais do planeta terra. E, umas séries de princípios 
SILVA, C. A. da; SILVA, L. de S; BRITO, A. K. R; LIMA, A. M. de A.

que os países desenvolvimentos e em desenvolvimento com as obrigações de contribuírem para preservar o meio ambiente.

O Brasil, a partir de 1981, outorgou a Política Nacional do Meio Ambiente, gestado hoje, pelo Ministério do Meio Ambiente. No Estado do Amazonas, a agricultura familiar Noda, (2007, p. 54-56). Há décadas vêm realizado atividades agrícolas sem, contudo, degredar o ambiente. E, pela circunstância de percurso, conforme assinalados nos princípios das convenções sobre o desenvolvimento sustentáveis. As famílias vêm realizando a sustentabilidade por meio de atividades de baixos índices de impactos, porém sempre há a ausência do poder público junto aos feitores de agricultura familiar. É que se tem identificados às margens dos rios ao longo de 40 anos na região.

\section{REFERÊNCIAS}

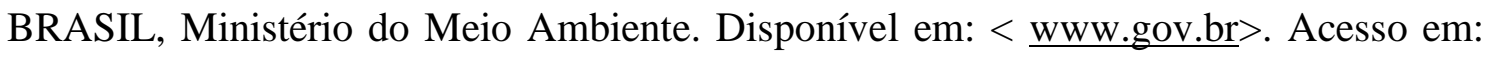
mar., 2014.

BRUSEKE, Franz Josef. O Problema do Desenvolvimento Sustentável. In: Desenvolvimento e Natureza: Estudos para uma sociedade sustentável. (Org.) CAVAlCANTE, Clóvis. São Paulo: Cortez, Recife, PE. Fundação Joaquim Nabuco, 1995.

CARVAJAL, Gaspar de. Descobrimento do Rio de Orellana. São Paulo/Rio de Janeiro: Companhia Editora Nacional, 1941. (trecho entre o rio Negro e Tapajós).

ENRÍQUEZ, Maria Amélia. Trajetórias do desenvolvimento: da ilusão do crescimento ao imperativo da sustentabilidade. Rio de Janeiro: Garamond, 2010.

FRAXE, Terezinha de J. P. Cultura Caboclo-Ribeirinha: Mitos, lendas e transculturalidade. 2. a edição, São Paulo: Annablume, 2010.

FONSECA, Ozorio J.M. Pensando a Amazônia. Manaus: Editora Valer, 2011.

MORAN, Emilio F. A Ecologia Humana das Populações da Amazônia. Petrópolis, RJ: Vozes, 1990.

NODA, Sandra do Nascimento. Agricultura Familiar na Amazônia das Águas. (Org.). Manaus: Editora da Universidade Federal do Amazonas, 2007.

SIRVINSKAS, Luís Paulo. Manuela de Direito Ambiental. $7^{\mathrm{a}}$ ed., rev. atual e ampl. São Paulo: Saraiva, 2009.

SOARES, Fernando Silva. A Proteção Internacional do Meio Ambiente. Barueri, São Paulo: Manoel, 2003.

STAHEL, Andri Wener. Capitalismo e entropia: Os aspectos ideológicos de uma contradição e a busca de alternativas sustentáveis. In: (Org.) CAVALCANTE, Clóvis. São Paulo: Cortez, Recife, PE. Fundação Joaquim Nabuco, 1995. 